\title{
XXII. Photo-electric fatigue
}

\section{J. Robinson M.Sc. Ph.D.}

To cite this article: J. Robinson M.Sc. Ph.D. (1912) XXII. Photo-electric fatigue, Philosophical Magazine Series 6, 23:134, 255-263, DOI: 10.1080/14786440208637219

To link to this article: http://dx.doi.org/10.1080/14786440208637219

册 Published online: 08 Jun 2010.

6 Submit your article to this journal $\pi$

LII Article views: 2

Q View related articles $₫$ 
The following table gives the viscosities deduced from a comparison of transpiration times : the same conditions do not hold throughout, but only for each comparison.

\begin{tabular}{|c|c|c|c|}
\hline Gas. & $\begin{array}{c}\text { Mean Ratio of Transpiration } \\
\text { time to that of Air. }\end{array}$ & Mean Temp. & $\mu$. \\
\hline Air ................ & Direct calculation. & $11^{\circ .75 \mathrm{C} .}$ & .000180 \\
Hydrogen ......... & $\frac{48.5}{\overline{101.0}}$ & $12^{\circ .25 \mathrm{C} .}$ & $.000086 \pm$ \\
Carbon dioxide... & $\frac{60.8}{75.5}$ & $12^{\circ} .60 \mathrm{C}$. & .000145 \\
Coal-gas ........... & $\frac{560}{755}$ & $12^{\circ} .90 \mathrm{C}$. & .000133 \\
\hline
\end{tabular}

I take the opportunity of thanking Professor Wilberforce for constant interest and advice, in this and in other work.

George Holt Physics Laboratory, University of Liverpool.

XXIt. Photo-Electric Fatigue. By J. Robinson, M.Sc., Ph.D., Demonstrator in Plysics at the Lniversity of Sheffield* . COME very interesting results on photo-electric fatigue $\bigcirc$ were given by $\mathrm{H}$. Stanley Allen in the Phil. Mag. for October 1910. He showed that the fatigue takes place practically at the same rate in darkness as in light, that it is independent of the electric field, but that the size of the vessel used has an influence on it. Some results which are brought forward in the following seem at first sight contradictory to thuse of Allen. To understand these differences, it will be necessary to consider closely the conditions uuder which the different experiments were made.

Allen polished his plates immediately before an experiment, and measured the photo-electric currents at atmospheric pressure directly afterwards, making measurements at regular intervals. He found the current to diminish with the time, and the rate of diminution to be independent of light.

In the present experiments, the electrodes were polished by rubbing with steel, and inserted in a glass vessel which was pumped out to a high vacuum as quickly as possible. The experiments were made under these conditions, and extended

* Communicated by the Author. 
over some weeks, during which time the vacuum was constantly maintained.

The general arrangement of the apparatus was as follow:-

The electrode $A$ was insulated by an amber $\operatorname{rod} B$, which was fastened by sealing-wax into the glass vessel. $C$ is an

Fig. 1.

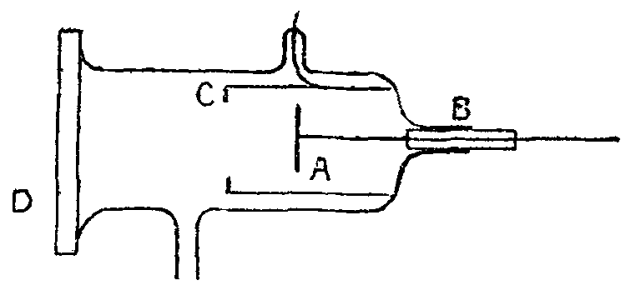

earthed metal tube with a hole in it to let the light through. The vessel was closed by a quartz plate $\mathrm{D}$. Three different sources of ultra-violet light were used on different occasions, two quartz-mercury lamps, and an aluminium spark *.

Experiments were made to investigate whether there is a fatigue due to the action of ultra-violet light, and whether such fatigue depends on the electric field.

\section{Experiments with a Zinc Electrode.}

The electrode was connected to one pair of quadrants of a Dolezalek electrometer. When ultra-violet light falls on the rinc, the latter charges positively. The electrode was insulated and allowed to charge itself up positively under the action of light, and its potential at definite intervals noted. Firstly, this rate was measured when the light was allowed to fall on the electrode which had been in the dark for a long time, and was in a condition which will be deseribed as fresh. Secondly, light was allowed to fall on the electrode for a certain length of time, say 5 minutes, after which time the rate of charging was measured as before. Thirdly, light was allowed to fall on the electrode for 5 minutes, but electrons were prevented from leaving the electrodes during this time by keeping it charged to a positive potential. Then it was insulated, and the rate of charging measured as before.

* The experiments were made partly at the Armstrong College, Newastle-on-Tyne, and partly at the University of Sheffield. 
TABLE I.

\begin{tabular}{|c|c|c|c|c|c|}
\hline \multicolumn{2}{|c|}{ Fresh Electrode. } & \multicolumn{2}{|c|}{$\begin{array}{l}\text { Electrode after being } \\
\text { exposed to light for } \\
5 \text { minutes at }+10 \text { volts. }\end{array}$} & \multicolumn{2}{|c|}{$\begin{array}{l}\text { Electrode after being } \\
\text { exposed for } 5 \text { ninutes } \\
\text { at Zero Potential. }\end{array}$} \\
\hline Time. & Charge. & 'Time. & Charge. & Tine. & Charge. \\
\hline 30 secs. & 60 & 30 secs. & 65 & 30 secs. & 38 \\
\hline $60 "$ & 74 & $60 "$ & 75 & 60 & 56 \\
\hline 90, & 79 & $90 "$ & 77 & 90 & 64 \\
\hline 120, & 79 & 120 & 80 & 120 & 70 \\
\hline & & 150, & 80 & 150, & 74 \\
\hline & & & & 180 & 77 \\
\hline & & & & 210 & 79 \\
\hline
\end{tabular}

This table and the corresponding curves (fig. 2) show that the rate of charging of the zinc electrode is the same

Fig. 2.

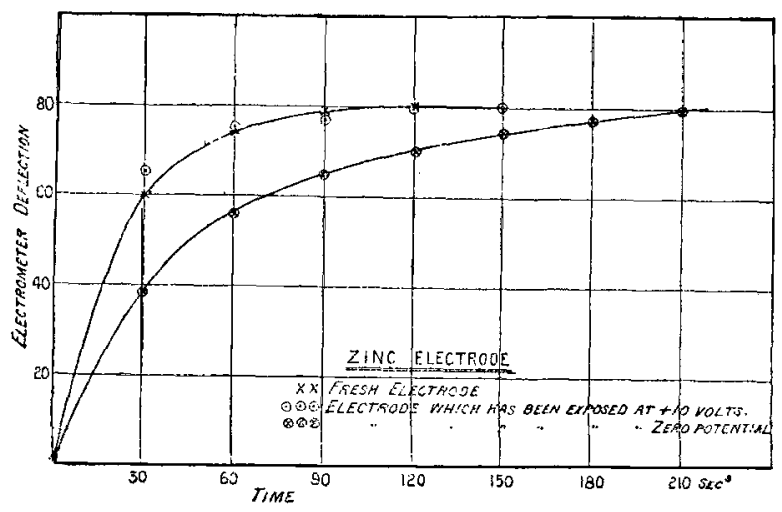

throughout for the fresh electrode, and when it has been exposed to light but maintained at a potential of 10 volts positive. When the electrode was exposed to ultra-violet light at zero potential its rate of charging was diminished, or, in other words, the electrode was fatigued. 


\section{Aluminium Electrode.}

Similar measurements were made with an aluminium electrode.

Table II.

\begin{tabular}{|c|c|c|c|c|c|}
\hline \multicolumn{2}{|c|}{ Fresh Electrodo. } & \multicolumn{2}{|c|}{$\begin{array}{l}\text { Fatigued Electrode } \\
\text { atter exposure to light } \\
\text { for } 5 \text { minutes. }\end{array}$} & \multicolumn{2}{|c|}{$\begin{array}{l}\text { Recovered Eiectrode } \\
\text { after rest of } 5 \text { minutes. }\end{array}$} \\
\hline Time. & Charge. & Time. & Charge. & Time. & Charge. \\
\hline 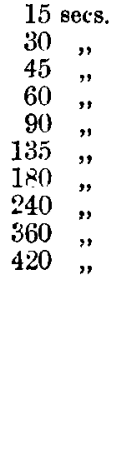 & $\begin{array}{l}176 \\
201 \\
220 \\
290 \\
241 \\
254 \\
260 \\
271 \\
271 \\
271\end{array}$ & 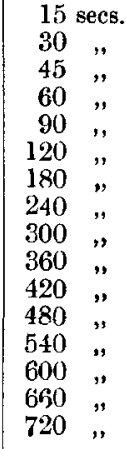 & $\begin{array}{r}58 \\
86 \\
101 \\
114 \\
130 \\
145 \\
166 \\
179 \\
196 \\
208 \\
215 \\
224 \\
233 \\
235 \\
239 \\
245\end{array}$ & 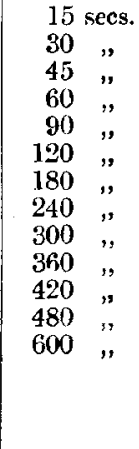 & $\begin{array}{l}176 \\
206 \\
218 \\
234 \\
250 \\
261 \\
269 \\
274 \\
274 \\
278 \\
278 \\
280 \\
286\end{array}$ \\
\hline
\end{tabular}

Fig. 3.

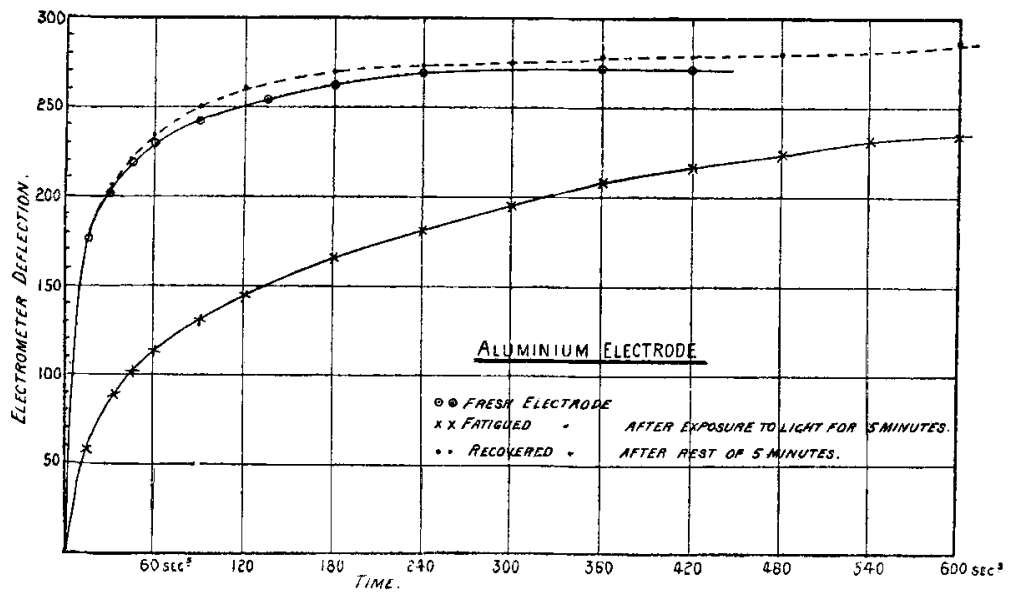


Fig. 4.

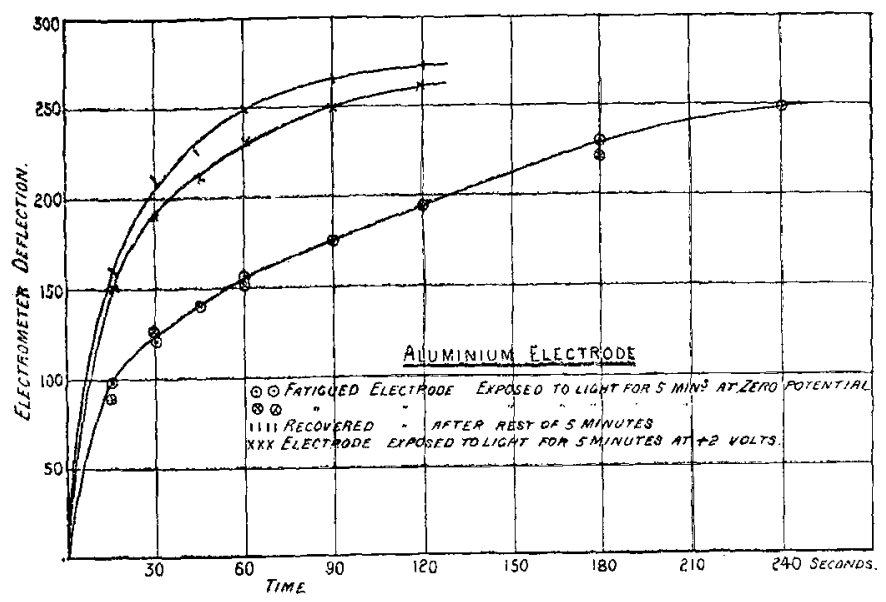

I'ABLE III.

\begin{tabular}{|c|c|c|c|c|c|c|c|}
\hline \multicolumn{2}{|c|}{$\begin{array}{l}\text { Electrode after } \\
\text { being exposed to } \\
\text { light for } 5 \text { minutes } \\
\text { at Zero Potential. }\end{array}$} & \multicolumn{2}{|c|}{$\begin{array}{l}\text { Recovered Elec } \\
\text { trode, after a rest } \\
\text { of } 5 \text { ninutes. }\end{array}$} & \multicolumn{2}{|c|}{$\begin{array}{l}\text { Electrode after } \\
\text { being exposed to } \\
\text { light for } 5 \text { minutes } \\
\text { at }+2 \text { volts. }\end{array}$} & \multicolumn{2}{|c|}{$\begin{array}{l}\text { Fatigued Elec- } \\
\text { trode, after } \\
\text { exposure to light } \\
\text { for } 5 \text { minutes at } \\
\text { Zero Yotential. }\end{array}$} \\
\hline Time. & Charge. & Time. & Charge. & Time. & Charge. & Time. & Charge. \\
\hline 15 secs. & 100 & $15 \mathrm{secs}$. & 160 & 15 secs. & 150 & 15 secs. & 90 \\
\hline 30, & 120 & 30, & 210 & 30, & 190 & 30 & 125 \\
\hline 45 & 140 & 45 & 225 & 45 & 210 & 45 & 140 \\
\hline 60 & 155 & 60 & 250 & 60 & 230 & 60 & 150 \\
\hline 120 & 195 & 90 & 265 & $90 \quad$, & 250 & 90 & 175 \\
\hline 180 & 230 & 120 & 272 & 120 & 260 & 120 & 195 \\
\hline 240, & 248 & ...... & ...... & $\ldots \ldots$ & ...... & 180 & 220 \\
\hline
\end{tabular}

These tables and curves for aluminium show the same characteristies as those for zinc.

Experiments of a different nature were also made to test the same points for aluminium. These were to measure the photo-electric currents under different conditions. The current was measured by joining the quadrants of the electrometer through a very high resistance, thus using the electrometer is a galvanometer. The current was measured, 1st. for the fresh electrode, snd, after it had been cxposed to light for 
some time at zero potential, and, 3rd, after it had been exposed at a positive potential.

TABLE IV.

\begin{tabular}{|c|c|}
\hline Condition of Electrode. & Current \\
\hline 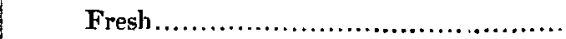 & 42 \\
\hline 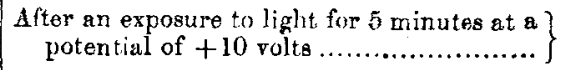 & 42 \\
\hline 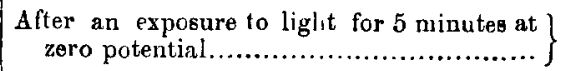 & 13 \\
\hline 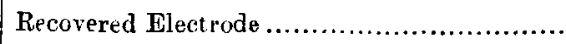 & 42 \\
\hline
\end{tabular}

TABLE V.

\begin{tabular}{|c|c|}
\hline Condition of Electrode. & Current. \\
\hline Fresh...................................... & 40 \\
\hline Exposed to light for 1 minute ..................... & 25 \\
\hline Rest of 7 minutes $\ldots . . . \ldots \ldots . . .$. & 42 \\
\hline Exposed for 2 minutes & 18 \\
\hline Rest of 5 minutes ..... & 41 \\
\hline 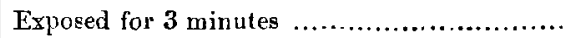 & 18 \\
\hline
\end{tabular}

TABLE VI.

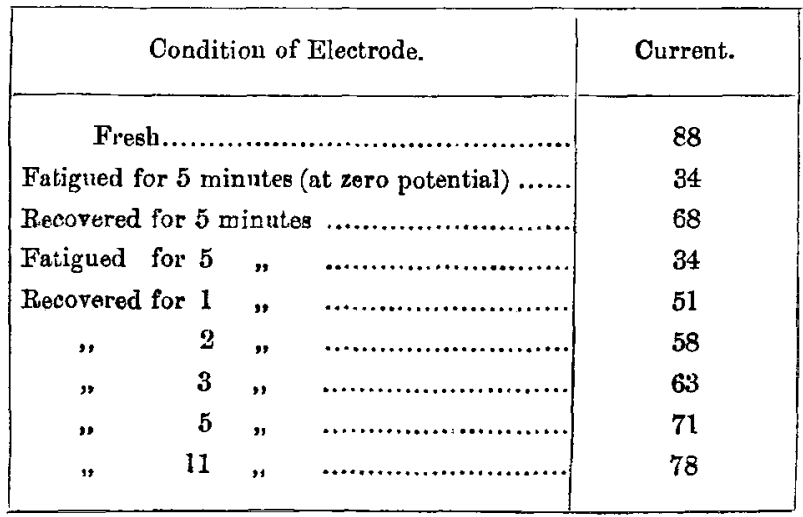

The general results of these experiments are (1) that a metal is fatigued by exposure to ultra-violet light; and after 
the light is shut off it begins to recover its original activity again, only becoming fresh again after a few minutes; (2) that the metal is fatigued only when it gives off electrons under the action of ultra-violet light.

Thus there is a real photo-electric fatigue, $i$. e. one due to the action of light, as opposed to that fatigue observed by Allen.

The result that the fatigue is only observable when electrons are emitted is worthy of some little consideration. Hallwachs* considered number of possible causes of photo-electric fatigue, and came to the conclusion that the chief cause is the gas occluded in the metal. 'The kind of fatigue that he investigated was of a similar nature to that mentioned by Allen. A possible explanation of the results of this paper can be obtained on Hallwachs's view. When the electrons leave a metal there will be a steady stream of them from a certain depth of the metal, and it is fair to suppose that some of them will bring molecules of the occluded gas to the surface, thus increasing the amount of gas there for the time being. For these electrons, giving rise to the photo-electric effect, which have a small velocity, gas has a large absorption coefficient $\dagger$; so that as the gas accumulates at the surface fewer electrons can get through, thus accounting for the decrease in the photoelectric current. On the other hand, when the electrons cannot leave the metal, by having the latter charged positively, there will be no stream of electrons to the surface, and so no accumulation of gas there.

The explanation of the recovery of the photo-electric current on this view is that the gas will diffuse from the surface either back into the metal or out of the metal, when the light is shut off, leaving the gas in the metal uniformly distributed over it.

Some support of the above view is given by the fact that very thin electrodes which have been in a vacuum for some time show no photo-electric fatigue. This has been shown for thin aluminium leaf and for a rery thin deposit of platinum on quartz.

A point which needs further consideration is why the particles of gas when carried to the surface of the metal by the electrons do not leave the metal altogether, instead of accumulating there. One may consider that there is some surface effect to account for this. Hallwachs has discussed such a possibility, and tried experimentally, but without

* Ann. der Phys. xxiii. p. 459 (1907).

t Lenard, Amn. der Phys xii. p. 714 (1903); Robinson, Amm. der Phys. xxxi. p. $809(1910)$. 
suczess, to establish somp relation between photo-electric fatigue and contact potential *. Lenard $\dagger$ came to the conclusion some time ago that such a surface-layer must exist. 'The following experiments seem to argue in favour of the existence of such a layer.

It was found that the final positive potential taken up by the zinc electrode under the action of light was by no means constant. Starting with it at the same potential as the metal cylinder surrounding it, $i$. e. earthed, its potential as registered by the deflexion of the electrometer-needle rose rapidly at first, after the light was put on, and then rose much more slowly (fig. 2). The typical form of the curve can be divided into these two parts, of rapid rise and of slow rise. In all curves, the first part was always of the same form, but the second part varied very much, especially if the light was allowed to fall on the metal for a long time. Sometimes it remined parallel to the axis of time for some minutes and then commenced to rise; at other times it increased gradually all the time, and sometimes it increased very slowly at first and then suddenly began to rise rapidly. It might be mentioned that this was also found to be the case when monochromatic light was used, so that the light was of small intensity.

$\Lambda$ satisfactory explanation of this has not been attempted, but very probably it has something to do with a double layer at the surface of the metal.

The conclusions to be drawn from this paper are entirely different from Allen's. Here a real photo-electric fatigue has been observed. The point to be considered in connexion with Allen's results is whether the main thing he investigated was photo-electric fatigue, or whether the fatigue be observed was merely of secondary importance, occurring as a result of some other effect. Very possibly the surtaces of his electrodes were not in a stable condition just after polishing, and some sort of readjustment of the surface sets in immediitely. This would occur quite independently of the action of light or of the electric field. A similar phenomenon has been observed by the present writer. When quartz-fibres are made conducting by depositing a metal on them from a cathode in a discharge-tube, the electrical resistance of the fibre varies very much after coming into the atmosphere. When the tibre is coated with platinum the resistance increases with the time, and when it is coated with copper it may become

* Loc. cit.

$\dagger$ Ann. der Phys. xii. p. 449 (1903). 
an absolute insulator again after a few hours. There is possibly some connexion between this alteration of resistance of thin films and the photo-electric fatigue mentioned by Allen, and some experiments are being made at present to test it.

I have great pleasure in recording my best thanks to Professor Strond, of the Armstrong College, Newcastle-on-'Tyne, and to Professor W. M. Hicks, of the University of Sheffield, for the use of the apparatus necessary for the aboro experiments.

XXIII. The Electron Theory of Contact Elertromotive Forre and Thermolectricity. By O. W. Richandoson, Professor. of Physics, Princeton University *

$r$ THE following method of deducing certain formula which 1 connect some of the physical properties of conductors, particularly in the domain of thermoelectricity, with the number and state of the free electrons present in them, is a natural development of considerations which the writer put forward some time ago in order to aceount for the laws whish regulate the emission of negative electrons from hot bodies + . The method is based on two fundamental assumptions. The first, which is common to all forms of the electron theory of metallic conduction, is that the electric current in melals is carried by electrons which move about freely, exert a pressure, and are otherwise dynamically equivalent to the molecules of a gas. The second is that the potential energy of an electron is much less when it is inside an uncharged conductor than when it is extracted and removed to a considerable distance. It follows that a definite amount of work $w$ has to be done by an electron before it can escape from a conductor, and it is the force at the interface, which corresponds to this amount of work, which retains the electrons in the conductor at ordinary temperatures.

This position has recently been strengthened by an accumulation of experimental evidence. It has been found to give an adequate quantitative explanation of the number of electrons emitted by hot bodies under different conditions. The emitted electrons have been found to bave a distribution of velocity in accordance with the requirements of Maxwell's law, and to have a mean translatory kinetic energy identical

* Conmunicated by the Author.

+ Camb. Phil. Proc. vol. xi. p. 286 (1901); Phil. Trans, A. vol. cei. p. 497 (1903). 